\title{
Application of a conventional fishery model for assessment of entrainment and impingement impact
}

\author{
Alvin L. Jensen \& Ted A. Hamilton \\ School of Natural Resources, University of Michigan, Ann Arbor, Michigan 48109, U.S.A.
}

\section{Keywords:}

Dynamic pool model, Lake Erie, Fishery, Yellow perch

\section{Synopsis}

A conventional stock assessment model is applied to determine the impact of entrainment and impingement at the Monroe Power Plant on the yellow perch stock of the Western basin of Lake Erie. Parameters of the model are estimated using power plant data, biological data available in the literature, and commercial catch data. The model is applied to estimate the age structure and biomass of the perch stock and to estimate the impact of the power plant on abundance of the impingeable stock and abundance and biomass of the exploited stock. The level of impact was examined under a range of mortality conditions. Under the most extreme conditions examined of full pumping, high fishing mortality, and low natural mortality, the fishable biomass is reduced by $1.7 \%$. This impact is not large, but there are several other power plants and many additional water intakes around the Western basin of Lake Erie.

\section{Introduction}

A conventional fishery model is applied to determine the impact of entrainment and impingement of the Monroe Power Plant on the yellow perch (Perca flavescens) population of the Western basin of Lake Erie. The model expresses impingement, entrainment, and yield as functions of growth, natural mortality, and reproduction. The growth and natural mortality parameters were estimated using biological data available in the literature. A catch equation was applied to estimate recruitment and stock size from estimates of catch, natural mortality, and fishing mortality. This approach gives an estimate of stock size and enables estimation of the relative impact of entrainment and impingement. Entrainment and impingement parameters were estimated using power plant data. The impact on stock numbers and biomass is assessed under a range of natural and fishing mortalities. This study was supported by a grant from the U.S. Environmental Protection Agency.

\section{The power plant}

The Monroe Power Plant, operated by the Detroit Edison Company, is a coal-fired 3,150 megawat electric generating station located on the Western shore of Lake Erie just south of the confluence of the Raisin River. The water demand of the oncethrough cooling system depends on power production and ambient water temperature. The maximum pumping capacity is about $2.8 \times 10^{9} \mathrm{~m}^{3}$ per year. Water is pumped in varying proportions from the Raisin River and Lake Erie.

Data for assessment of the impact of the plant are based on 52 weeks of sampling at the site, from April 1975 to April 1976, with the entrainment and impingement studies conducted concurrently. All sampling was done by Detroit Edison Company biologists (Anon. 1976). The mean operational load during the sampling days was $55.7 \%$ of the maximum rated capacity. Over the 12 -month period an estimated total of 861,000 fish were impinged, of which $51.8 \%$ were gizzard shad and $14.2 \%$ were yellow perch.

An estimated 21,392,679 larvae were entrained. 
of which nearly $45 \%$ were gizzard shad. Yellow perch accounted for approximately $23 \%$ of the total. In addition to fish larvae, fish eggs also were entrained by the power plant. From April 1975 to April 1976, a total of 13,083,131 eggs were entrained. The family Clupeidae accounted for the largest number of entrained eggs $(2,865,375)$ while yellow perch accounted for about $0.7 \%$ of the total identified. However, about $77 \%$ of the eggs were unidentified.

\section{Development of the model}

The impact of entrainment and impingement is assessed using the dynamic pool model, a conventional stock assessment model that has been widely applied for assessment of the impact of fishing on fish stocks (Gulland 1969, Ricker 1975). In application of conventional stock assessment models the stock is separated into two portions. The recruited stock is the portion of the stock vulnerable to fishing. The unrecruited stock is the younger life stages not captured by the fishing gear. Stock assessment models are developed for the exploited stock for which data are usually available (Gulland 1969, Ricker 1975). Fishery scientists have generally avoided the younger life stages in stock asscssment because it is difficult to obtain reliablc data for them. For assessment of the impact of entrainment the entire life history must be examined at least indirectly.

Assuming the same functional forms for power plant impacts as for fishing, the dynamic pool model modified for entrainment and impingement is:

$$
\begin{aligned}
& \frac{d Y}{d x}=F N W, x>x_{c}, \\
& \frac{d N}{d x}=-(F+M+f Q) N, x>x_{c}, \\
& \frac{d N}{d x}=-(f Q+M) N, x_{I}<x \leq x_{c}, \\
& \frac{d W}{d x}=3 W_{\infty} K^{-K\left(x-x_{0}\right)}\left[1-e^{-K\left(x-x_{0}\right)}\right]^{2}, \\
& \frac{d I}{d x}=f Q N, x>x_{I}, \\
& \frac{d E}{d x}=-\left(M_{1}+g Q\right) E, x>x_{L},
\end{aligned}
$$

$$
\begin{aligned}
& \frac{\mathrm{dE}_{\mathrm{e}}}{\mathrm{dx}}=\mathrm{g} Q \mathrm{E}, \mathrm{x}>\mathrm{x}_{\mathrm{L}}, \\
& \frac{\mathrm{dL}}{\mathrm{dx}}=-\left(\mathrm{M}_{2}+\mathrm{hQ}\right) \mathrm{L}, \mathrm{x}_{\mathrm{L}}<\mathrm{x}<\mathrm{x}_{\mathrm{I}} \text {, and } \\
& \frac{\mathrm{dL}_{\mathrm{e}}}{\mathrm{dx}}=\mathrm{h} \mathrm{Q} \mathrm{L}, \mathrm{x}_{\mathrm{L}}<\mathrm{x}<\mathrm{x}_{\mathrm{I}},
\end{aligned}
$$

where:

$\mathrm{Y}=$ annual yield from the fishery, $\mathrm{N}=$ number of individuals of age $\mathrm{x}, \mathrm{W}=$ weight of an individual of age $x, F=$ instantaneous fishing mortality coefficient, $M=$ instantaneous natural mortality coefficient, $\mathbf{M}_{1}=$ instantaneous natural mortality coefficient of eggs, $\mathbf{M}_{2}=$ instantaneous natural mortality coefficient of larvae, $\mathrm{W}_{\infty}=$ asymptotic individual weight, $\mathrm{K}=$ growth coefficient, $\mathrm{x}_{0}=$ theoretical age when length equals zero, $x_{c}=$ age when individuals become vulnerable to the fishing gear, $x_{1}=$ age when fish become vulnerable to impingement, $\mathrm{x}_{\mathrm{L}}=$ duration of egg stages, $I=$ number of age $\times$ fish impinged, $Q=$ annual intake flow rate, $f=i m-$ pingement coefficient, $\mathrm{g}=\mathrm{cgg}$ entrainment coefficient, $\mathrm{h}=$ larvae entrainment coefficient, $\mathrm{E}=$ number of eggs, $\mathrm{E}_{\mathrm{e}}=$ number of eggs entrained at time $x, L=$ number of larvae, and $L_{e}=$ number of larvae entrained at time $\mathrm{x}$.

The above equations can be solved in closed form to obtain equations for eggs, larvae, number of individuals, and biomass (Gulland 1969).

The model is applied to determine the proportions of eggs and larvae entrained and the proportion of the population of age $x>x_{I}$ impinged. These impacts were estimated using the equations:

$$
\begin{aligned}
& \begin{array}{l}
\text { propertion of eggs } \\
\text { entrained }
\end{array} \\
& \begin{array}{l}
\text { proportion of larvae } \\
\text { entrained }
\end{array}=\frac{\Delta \mathrm{E}}{\phi \mathrm{pN}_{\mathrm{m}}}, \\
& \begin{array}{l}
\phi \mathrm{pN}_{\mathrm{m}} \mathrm{e}^{-\left(\mathrm{M}_{1}+\mathrm{g} \mathrm{Q}\right) \Delta \mathrm{tE}} \\
\text { proportion of adults } \\
\quad \text { impinged }
\end{array}=\frac{\Delta \mathrm{N}}{\mathrm{N}} .
\end{aligned}
$$

Reductions in the numbers, $N_{m}$, and biomass, $B$, of the fishable stock (ages $\mathrm{x}>\mathrm{x}_{\mathrm{c}}$ ) were calculated as:

$$
\text { reduction in } \mathrm{N}_{\mathrm{m}}=\frac{\text { decrease in } \mathrm{N}_{\mathrm{m}}}{\mathrm{N}_{\mathrm{m}} \text { without plant }} \text {, }
$$


reduction in $\mathrm{B}=\frac{\text { decrease in } \mathrm{B}}{\mathrm{B} \text { without plant }}$.

These calculations were done using full volume flow and both entrainment and impingement impacts.

\section{Estimation of parameters}

The growth parameters for yellow perch, $\mathrm{K}, \mathrm{W}_{\infty}$, and $\mathrm{x}_{0}$, were estimated using the conventional methods described by Gulland (1969) and the data reported by Jobes (1952) on a sample of 23,158 fish collected from Lake Erie. Parameter estimates are listed in Table 1. Other more recent data sets for yellow perch in the Great Lakes and elsewhere indicate only a small range of parameter values (Brazo et al. 1975, Thorpe 1977).

Table 1. Summary of estimates of parameters that were held constant over all cases.

\begin{tabular}{|c|c|c|}
\hline Parameter & symbol & value \\
\hline Growth coefficient & $\mathrm{K}$ & 0.45 \\
\hline Asymptotic weight $(\mathrm{kg})$ & $\mathrm{W}_{\infty}$ & 0.34 \\
\hline $\begin{array}{l}\text { Theoretical age when } \\
\text { length is zero }(\mathrm{yr})\end{array}$ & $x_{0}$ & 0.21 \\
\hline $\begin{array}{l}\text { Number of eggs produced } \\
\text { per female }\end{array}$ & $\phi$ & 20,000 \\
\hline Duration of egg stages (yr) & $d \mathrm{t}_{\mathrm{E}}$ & 0.027 \\
\hline $\begin{array}{l}\text { Minimum proportion of } \\
\text { eggs hatching }\end{array}$ & $\mu$ & 0.25 \\
\hline Duration of larval period (yr) & $\Delta \mathrm{t}_{\mathrm{L}}$ & 0.57 \\
\hline Impingeable age & $x_{1}$ & 1 \\
\hline Age at entry to fishery & $x_{c}$ & 3 \\
\hline
\end{tabular}

Egg entrainment coefficients were estimated as

$$
\hat{\mathrm{g}}=\frac{\Delta \mathrm{E}}{\mathrm{Q} \phi \mathrm{pN}_{\mathrm{m}}}
$$

where:

$\Delta \mathrm{E}=$ the number of eggs entrained in one year, $\phi=$ the average number of eggs produced per female, and $\mathrm{p}=$ the proportion of sexually mature adults that are females.

Of the eggs identified 86,528 were yellow pcrch, but $77 \%$ of the eggs were not identified. Assuming the same species and proportions for eggs not identified as for those that were identified gives a total of 379,411 yellow perch eggs entrained. The entrainment coefficients were calculated using both of these values for egg entrainment (Table 2). Volume flow was estimated as $1.6 \times 10^{9} \mathrm{~m}^{3}$ per yer. Eddy \& Surber (1943) estimated the number of eggs produced per yellow perch female, $\phi$, as 20,000 . The proportion of females, $p$, equals 0.50 (Jobes 1952).

The mortality rates $M$ and $F$ are difficult to estimate because adequate data for separation of natural and fishing mortality are not available. In this study results were examined using a range of mortality coefficients. Survival data for the period 1971-1975 (Scholl 1976) give the total mortality coefficient, $Z$, as 0.82 year $^{-1}$. The range for the fishing mortality coefficient is based on the assumption that 20 to 40 percent of all perch vulnerable to fishing will be harvested annually by sport and commercial fishermen. Under this assumption, the instantaneous fishing mortality coefficient, F, is in the interval $(0.22,0.51)$. A reasonable range of values for $M$ is $(0.22,0.60)$ which gives values of $Z$ in the interval $(0.44,1.11)$. This includes the estimated value of 0.82 near the mid-point. Hartman (1977) estimated the instantaneous natural mortality coefficient, $M$, to be in the range of 0.22 to 0.29 .

To calculate $B$ and $N$ the number of recruits or individuals of age $x_{I}$ must be calculated. An equation for cstimation of recruitment, $\mathrm{R}$, was $\lrcorner$ btained from the catch equation $\mathrm{dC} / \mathrm{dx}=\mathrm{FN}$. Substitution of $N_{m}$ for $x>x_{c}$ from equations (1) into the catch equation, integration, and solution for $\mathrm{R}$ gives

$$
\mathrm{R}=(\mathrm{M}+\mathrm{F}+\mathrm{fQ}) \mathrm{C} \mathrm{e}^{(\mathrm{M}+\mathrm{f} Q)\left(\mathrm{x}_{\mathrm{c}} \times \mathrm{x}\right)},
$$

where $C$ is the annual catch. In 1975 the annual catch was estimated from commercial catch and average weight data as $7.5 \times 10^{6}$.

The egg and larvae mortality coefficients were estimated under the assumption that the population is in a steady-state and that egg production and recruitment are balanced. The number of eggs produced and the number of recruits depend on $M$ and $F$. For each case of natural and fishing mortality the egg and larvae mortality coefficients were calculated as $\mathrm{M}_{1}=\left(1 / \Delta \mathrm{t}_{\mathrm{E}}\right) \ln (\mathrm{L} / \mathrm{E})$ and $\mathrm{M}_{2}=$ $\left(1 / \Delta \mathrm{t}_{\mathrm{L}}\right) \ln (\mathrm{R} / \mathrm{L})$.

The larvae entrainment coefficient was estimated as

$$
\hat{\mathrm{h}}=\frac{\Delta \mathrm{L}}{\mu \phi \mathrm{pN}} \mathrm{m},
$$


Table 2. Estimates of parameters and variables that were varied from cse to case.

\begin{tabular}{|c|c|c|c|c|c|}
\hline \multirow[t]{2}{*}{ Parameler } & \multirow[t]{2}{*}{ Symbol } & \multicolumn{4}{|l|}{ Case } \\
\hline & & I & II & III & IV \\
\hline Fishing mortality coefficient & $\mathrm{F}$ & 0.22 & 0.51 & 0.51 & 0.22 \\
\hline Natural mortality coefficient & $\mathbf{M}$ & 0.22 & 0.60 & 0.22 & 0.60 \\
\hline Size of mature population $\left(x>x_{c}\right)$ & $\mathrm{N}_{\mathrm{m}}$ & $3.43 \times 10^{7}$ & $1.48 \times 10^{7}$ & $1.48 \times 10^{7}$ & $3.43 \times 10^{7}$ \\
\hline Eggs produced & $\mathrm{E}^{\mathrm{m}}$ & $3.43 \times 10^{11}$ & $1.48 \times 10^{11}$ & $1.48 \times 10^{11}$ & $3.43 \times 10^{11}$ \\
\hline Larvae produced & $\mathbf{L}$ & $8.57 \times 10^{10}$ & $3.70 \times 10^{10}$ & $3.70 \times 10^{10}$ & $8.57 \times 10^{10}$ \\
\hline Recruitment & $\mathbf{R}$ & $2.43 \times 10^{7}$ & $5.45 \times 10^{7}$ & $1.68 \times 10^{7}$ & $9.33 \times 10^{7}$ \\
\hline Total population size $\left(x>x_{1}\right)$ & $\mathbf{N}$ & $7.22 \times 10^{7}$ & $7.82 \times 10^{10}$ & $4.18 \times 10^{7}$ & $1.41 \times 10^{8}$ \\
\hline Impingment & $\mathrm{f}$ & $1.06 \times 10^{-12}$ & $9.77 \times 10^{-13}$ & $1.83 \times 10^{-12}$ & $5.42 \times 10^{-13}$ \\
\hline Egg entrainment coefficient & $\mathrm{g}^{a}$ & $1.57 \times 10^{-16}$ & $3.65 \times 10^{-16}$ & $3.65 \times 10^{-16}$ & $1.57 \times 10^{-16}$ \\
\hline Egg entrainment coefficient & $g^{b}$ & $6.91 \times 10^{-16}$ & $1.60 \times 10^{-15}$ & $1.60 \times 10^{-15}$ & $6.91 \times 10^{-16}$ \\
\hline Larval entrainment coefficient & $\mathrm{h}$ & $3.64 \times 10^{-14}$ & $8.44 \times 10^{-14}$ & $8.44 \times 10^{-14}$ & $3.64 \times 10^{-14}$ \\
\hline
\end{tabular}

a Assumes 86,528 eggs entrained which is the observed number.

${ }^{h}$ Assumes 379,411 eggs entrained which accounts for the $77 \%$ unidentified eggs.

where $\Delta \mathrm{L}$ is the number of larvae entrained annually which was estimated as $4,996,924$ in 1975 , and $\mu$ is the proportion of eggs from which embryo hatch to develop into larvae. Scholl (1976) reported that the minimum hatching success for yellow perch is approximately $25 \%$.

Yellow perch may spawn as early as late April or early May (Scholl 1976). Hatching takes place in 8 to 10 days but may take longer (Scott \& Crossman 1973). Assuming knife edge reproduction and that the average time required for hatching is 10 days the duration of the embryonic period egg stages, $\Delta \mathrm{t}_{\mathrm{E}}$, is 0.0274 years.

Perch larvae are recruited into the young-of-theyear 25 days after hatching (Patterson 1976). Combining the 25 day larval period with the following six-month period as young-of-the-year gives a yearly fraction when the fish are vulnerable to entrainment, $\Delta \mathrm{t}_{\mathrm{L}}$, of 0.5687 years.

At one year of age the adult perch become vulnerable to impingement so $x_{I}=1$. At three years of age they are recruited into the exploited stock $\left(x_{c}=3\right)$ and sexual maturity also is attained by the age of 3 for the majority of females (El-Zarka 1957).

The impingement coefficient was estimated as

$$
\hat{\mathrm{I}}=\frac{\Delta \mathrm{N}}{\mathrm{QN}}
$$

where the number impinged, $\Delta \mathrm{N}$, was estimated as 122,301. All estimates are listed in Tables 1 and 2.

\section{Results and discussion}

The impact which an additional mortality source, such as a power plant, will exert upon the fishable biomass and the population size is a function of natural and fishing mortality. Natural mortality is difficult to estimate and both natural and fishing mortality are variable, so four cases are examined that represent different possible combinations of natural and fishing mortality. This provided the assessment of a wide range of impacts on the yellow perch population size and biomass. In all cases entrainment impact is similar with egg entrainment coefficients based on 86,528 eggs and 371,411 eggs entrained; impacts listed in Table 3 were calculated with the observed number of eggs entrained.

Case I assumes that the adult population is experiencing low levels of fishing and natural mortality. This results in a fairly even balance of unexploitable and exploitable fish; with a total population estimated at about 72 million individuals. The proportions entrained and impinged are listed in Table 3. Under Case I the Monroe Power Plant operating at maximum capacity reduces the total adult population by $0.71 \%$. At full operating capacity the biomass is reduced by $1.32 \%$.

Case II assumes that the yellow perch population is subject to high fishing and high natural mortality. These conditions produce a population dominated by young fish between the ages of one and three. The total population is estimated at about 78 
Table 3. Summary of power plant impacts: proportions of eggs and larvae entrained, and proportion of adults $\left(x>x_{I}\right)$ impinged at observed flow $\left(1.6 \times 10^{9} \mathrm{~m}^{3}\right.$ per $\left.\mathrm{yr}\right)$. Decrease (proportion) in numbers and biomass of exploitable stock $\left(x>x_{c}\right)$ at full flow $\left(2.9 \times 10^{9} \mathrm{~m}^{3}\right.$ per yr $)$.

\begin{tabular}{|c|c|c|c|c|}
\hline \multirow[t]{2}{*}{ Impact } & \multicolumn{4}{|l|}{ Case } \\
\hline & I & Il & III & IV \\
\hline $\begin{array}{l}\text { Eggs } \\
\text { entrained }\end{array}$ & $2.52 \times 10^{-7}$ & $5.85 \times 10^{-7}$ & $5.85 \times 10^{-7}$ & $2.52 \times 10^{-7}$ \\
\hline $\begin{array}{l}\text { Larvae } \\
\text { entrained } \\
\text { Adults }\end{array}$ & $5.83 \times 10^{-5}$ & $1.35 \times 10^{-4}$ & $1.35 \times 10^{-4}$ & $5.83 \times 10^{-5}$ \\
\hline $\begin{array}{l}\text { impinged } \\
\text { Population }\end{array}$ & $1.69 \times 10^{-3}$ & $1.56 \times 10^{-3}$ & $2.91 \times 10^{-3}$ & $8.56 \times 10^{-4}$ \\
\hline $\begin{array}{l}\text { decrease } \\
\text { Biomass }\end{array}$ & $7.05 \times 10^{-3}$ & $3.24 \times 10^{-3}$ & $8.65 \times 10^{-3}$ & $2.00 \times 10^{-3}$ \\
\hline decrease & $1.32 \times 10^{-2}$ & $7.96 \times 10^{-3}$ & $1.75 \times 10^{-2}$ & $5.00 \times 10^{-3}$ \\
\hline
\end{tabular}

million; which is similar to that for the Case I population and hence the proportion impinged is also similar (Table 3). The number of sexually mature females is much less in this case and egg and larval production also are less, resulting in a greater entrainment impact. In spite of the greater impact duc to cntrainment, the total impact decreased the adult population by only $0.32 \%$. The fishable biomass was reduced by approximately $0.80 \%$. This represents a substantially lesser impact than that which results under Case I criteria.

Case III assumes the population is subject to low natural and high fishing mortality rates. These conditions produce a relatively small population of approximately 42 million fish which, again, is dominated by immature fish. The number of mature fish is the same as in Case II and therefore the egg and larval production also will be the same. Identical results also are obtained for egg and larval entrainment (Table 3). The proportion impinged, however, is greater because of the smaller population size.

The impact of the Monroe Power Plant operating at maximum capacity reduces the population by $0.87 \%$. The fishable biomass is reduced by $1.75 \%$.

Case IV assumes both a high natural mortality and a low fishing mortality operate on the population. These conditions produce a large population of approximately 143 million fish; 109 million of which are between the ages of one and three. The number of sexually mature females is quite small relative to the size of the population and is, in fact, the same as for Case I. It follows that the proportion of eggs and larvae entrained also is the same (Table 3). Due to the large population size the proportion impinged is smaller. Under the conditions of a maximum flow rate the population size is reduced by $0.2 \%$. The fishable biomass is decreased by $0.50 \%$.

These results indicate that the Monroe Power Plant has a relatively small impact on the yellow perch population in the Western basin of Lake Erie. The maximum reduction in fishable biomass of $1.75 \%$ occurs with a low natural mortality and a high fishing mortality, and these conditions might be most representative of the actual conditions in the lake. This impact is not large, but there are several other power plants located on the Western basin of Lake Erie and many municipal and industrial water intakes.

\section{References cited}

Anon 1976. Monroe Power Plant: study report on cooling water intake. Detroit Edison Company. Detroit, Michigan. 167 pp.

Beverton, R.J.H. \& S.J. Holt 1957. On the dynamics of exploited fish populations. U.K. Min. Agr. and Fish. Fish. Invest., Ser. 2, 19. $533 \mathrm{pp}$.

Brazo, D.C., P.I. Tack \& C.R. Liston 1975. Age, growth, and fecundity of yellow perch (Perca flavescens) in Lake Michigan. Trans. Amer. Fish. Soc. 104: 726-730.

Eddy, S. \& T. Surber 1943. Northern fishes. Univ. of Minn. Press, Minneapolis. 252 pp.

El-Zarka, S. 1959. Fluctuations in the population of yellow perch, Perca flavescens, in Saginaw Bay, Lake Huron. U.S. Fish. Bull. 59: 365 415 .

Gulland, J.A. 1969. Manual of methods for fish stock assessment. FAO Manuals in Fisheries Science No. 4. 154 pp.

Hartman, W.L. 1973. Effects of exploitation, environmental changes, and new species on the fish habitats and resources of lake Frie. Great Lakes Fish. Comm. Tech. Rept. No. 22 $43 \mathrm{pp}$.

Jobes, F.W. 1952. Age, growth, and production of yellow perch in Lake Erie. U.S. Fish. Bull. 52: 205-265.

Patterson, R.l. 1979. Production, mortality, and power plant entrainment of larval yellow perch in Western Lake Erie. EPA Research Report EPA-600/3-79-087. National Tech. Info. Service, $18 ; \mathrm{pp}$.

Ricker, W.E. 1975. Computation and interpretation of biological statistics of fish populations. Fish. Res. Board Can. Bull. 191. $382 \mathrm{pp}$.

Scholl, R.L. 1976. Status of Ohio's Lake Erie fisheries. Ohio Dept. Nat. Res. Div. Wildl. Lake Erie Fish. Invest. Study No. III. $20 \mathrm{pp}$.

Scott, W.B. \& E.J. Crossman 1973. Freshwater fishes of Canada. Fish. Res. Board Can. Bull. 184. 966 pp. 